\title{
Role of Tachycardia as an Inotropic Stimulus in Man
}

\author{
Donald R. Ricci, Arthur E. Orlick, Edwin L. Alderman, Neil B. Ingels, Jr., \\ George T. Daughters, iI, Catherine A. Kusnick, Bruce A. Reitz, and \\ EDWARD B. STINSON, Division of Cardiology and Department of Cardiovascular \\ Surgery, Stanford University Medical Center, Stanford, California 94305, and \\ Palo Alto Medical Research Foundation, Palo Alto, California 94301
}

A B S T RACT We examined the inotropic effect of tachycardia in nine postsurgical aortocoronary bypass graft patients (with intact cardiac innervation) and nine cardiac allograft recipients (with denervated hearts). The changes in stroke volume (SV) and velocity of circumferential fiber shortening (VCF) which accompany sudden increases and decreases in atrial pacing frequency were determined by computer-aided fluoroscopic analysis of the motion of surgically implanted midwall myocardial markers. Because the first beat after a change in rate retains the frequency characteristics of the preceding rate, we compared the first posttachycardia beat with control beats and late tachycardia beats with the first tachycardia beat; afterload and preload for each pair of beats were similar. For an increase in heart rate of 50 beats/min, SV and VCF rose 79 and $64 \%$ from the first tachycardia beat to late tachycardia beats, and SV and VCF rose 8 and 35\% from control beats to the first posttachycardia beat in the innervated group. Responses in the denervated group were not significantly different from those in the innervated group. The degree of the inotropic response was positively correlated with the magnitude of the increase in heart rate $(r=0.91)$. The decay in augmented contractility after decreasing the rate back to control levels fits an exponential relationship with a mean $t_{1 / 2}$ of $1.7 \mathrm{~s}$. Thus, in conscious man, increases in heart rate represent a positive inotropic stimulus, independent of other factors influencing ventricular performance and unaffected by neural innervation, and should be considered when changes in cardiac function are interpreted during serial studies or after drug administration.

Dr. Ricci was supported by the Canadian Heart Foundation. Dr. Stinson was supported in part by an Established Investigatorship of the American Heart Association.

Received for publication 27 October 1978 and in revised form 14 December 1978.

\section{INTRODUCTION}

Cardiac frequency influences performance of the intact ventricle not only by altering cardiac output at the extremes of heart rate, but also by a direct effect upon contractility (1). The extent of this direct contribution to contractility is commonly overlooked in man during evaluations of inotropic agents, most of which have concomitant chronotropic effects. Intrinsic inotropic drug effects in awake patients may be obscured by reflex adjustments that can attenuate drug effects. Moreover, in evaluating these effects in man, as compared with animal studies, there is difficulty maintaining constant the major determinants of ventricular performance such as heart rate, blood pressure, and filling pressures. Therefore we evaluated the extent to which increases in heart rate affect contractility in man, and examined both normally innervated subjects and cardiac allograft recipients whose hearts are devoid of extrinsic neural control. In addition, we sought to ascertain the time-course of these frequency-dependent changes in awake man.

Because of the difficulty in establishing the independent effect of cardiac frequency upon contractility in man, we used a technique modified after Mahler et al. (2) to compensate for changes in cardiac dimensions, systemic pressure, and possibly reflex adjustments which occur secondarily to heart rate changes. Our results suggest that increases in heart rate yield significant intrinsic improvements in contractility independent of changes in cardiac preload or afterload and unaffected by neural innervation.

\section{METHODS}

Patient characteristics. We studied 18 patients, aged 18-58 yr, whose clinical and hemodynamic features are presented in Table I. The first group comprised nine patients studied 4-10 d after saphenous vein aortocoronary bypass grafting. All patients had two or more grafts placed. Two patients had preoperative myocardial infarction, and two 
TABLE I

Resting Myocardial Dynamic Characteristics and Coronary Bypass Data

\begin{tabular}{cccccccc}
\hline Patient & HR $^{*}$ & EDV & SVI & CI & EF & VCF & $\begin{array}{c}\text { Left } \\
\text { ventriculogram }\end{array}$ \\
\hline beats/min & $m l / M^{2}$ & $m l / M^{2}$ & $\begin{array}{c}\text { liter/min/ } \\
M^{2}\end{array}$ & circum- \\
ferences/s
\end{tabular}

Patients with intact cardiac innervation after coronary artery surgery

\begin{tabular}{|c|c|c|c|c|c|c|c|c|}
\hline 1 & 97 & 80 & 47 & 4.54 & 0.59 & 1.25 & Nl & LAD, RCA, OM \\
\hline 2 & 118 & 49 & 30 & 3.57 & 0.61 & 1.17 & $\mathrm{Nl}$ & LAD, RCA, D, OM \\
\hline 3 & 82 & 134 & 59 & 4.87 & 0.45 & 0.86 & $\begin{array}{c}\text { Anterolateral } \\
\text { hypokinesis }\end{array}$ & LAD, OM \\
\hline 4 & 86 & 96 & 47 & 4.07 & 0.49 & 0.89 & $\mathrm{Nl}$ & LAD, OM \\
\hline 5 & 100 & 98 & 41 & 4.05 & 0.41 & 0.66 & $\begin{array}{l}\text { Inferior } \\
\text { hypokinesis }\end{array}$ & LAD, D, RCA \\
\hline 6 & 97 & 88 & 40 & 3.88 & 0.45 & 0.81 & $\begin{array}{l}\text { PIMI } \\
\text { Posterior } \\
\quad \text { hypokinesis }\end{array}$ & LAD, OM \\
\hline 7 & 92 & 68 & 32 & 2.93 & 0.46 & 0.80 & Nl & LAD, D \\
\hline 8 & 80 & 136 & 43 & 3.44 & 0.32 & 0.55 & $\begin{array}{l}\text { PAMI } \\
\text { Anteroapical } \\
\text { hypokinesis }\end{array}$ & LAD, D, OM, RCA \\
\hline 9 & 91 & 106 & 36 & 3.28 & 0.34 & 0.58 & $\mathrm{Nl}$ & LAD, PDA \\
\hline $\begin{array}{l}\text { Mean } \\
( \pm \text { SEM })\end{array}$ & $\begin{array}{l}94 \\
(4)\end{array}$ & $\begin{array}{c}95 \\
(9)\end{array}$ & $\begin{array}{l}42 \\
(3)\end{array}$ & $\begin{array}{c}3.85 \\
(0.20)\end{array}$ & $\begin{array}{c}0.46 \\
(0.03)\end{array}$ & $\begin{array}{c}0.84 \\
(0.08)\end{array}$ & & \\
\hline
\end{tabular}

Cardiac allograft recipients with denervated hearts

\begin{tabular}{|c|c|c|c|c|c|c|}
\hline 10 & 80 & 66 & 27 & 2.18 & 0.41 & 0.68 \\
\hline 11 & 86 & 82 & 39 & 3.34 & 0.48 & 1.17 \\
\hline 12 & 81 & 126 & 62 & 4.99 & 0.50 & 1.02 \\
\hline 13 & 100 & 45 & 27 & 2.67 & 0.58 & 0.84 \\
\hline 14 & 78 & 83 & 45 & 3.60 & 0.54 & 0.94 \\
\hline 15 & 97 & 71 & 35 & 3.49 & 0.49 & 0.74 \\
\hline 16 & 81 & 98 & 47 & 3.84 & 0.48 & 0.90 \\
\hline 17 & 75 & 58 & 30 & 2.26 & 0.51 & 0.87 \\
\hline 18 & 72 & 81 & 37 & 2.69 & 0.46 & 0.91 \\
\hline ean & 83 & 79 & 39 & 3.23 & 0.49 & 0.90 \\
\hline$( \pm$ SEM $)$ & (3) & (8) & (4) & $(0.30)$ & $(0.02)$ & $(0.05)$ \\
\hline$P \ddagger$ & NS & NS & NS & NS & NS & NS \\
\hline
\end{tabular}

*Abbreviations: HR, heart rate; SVI, stroke volume index; CI, cardiac index; EF, ejection fraction; CABG, coronary artery bypass graft; LAD, left anterior descending coronary artery; RCA, right coronary artery; OM, obtuse marginal coronary artery; D, left diagonal coronary artery; Nl, normal; PIMI, preoperative inferior myocardial infarction; PAMI, preoperative anteroseptal myocardial infarction.

$\$ P$, two-tailed analysis compared with innervated group.

additional patients had mild segmental wall hypokinesis in the area supplied by a stenotic vessel as determined by preoperative left ventriculography. No patient was receiving digoxin or other cardioactive medication and none had received sedatives or analgesics within $6 \mathrm{~h}$ of the study procedure. At the time of study, no patient had clinical signs of infection, fluid overload, or cardiac failure, and none had postoperative myocardial infarction. All had a low ejection fraction consistent with the mild myocardial depression associated with the early period after cardiopulmonary bypass (3), but none had a low cardiac index.

The second group comprised nine cardiac allograft recipients studied 4-10 wk after cardiac transplantation during a period of clinical stability. There were no clinical signs of infection, and a normal endomyocardial biopsy performed within 1 wk of study and favorable clinical features of graft stability (4) confirmed the absence of graft rejection at the time of study. Each patient had experienced the usual posttransplant diuresis that occurs during reestablishment of a normal extracellular fluid volume, and none displayed clinical evidence of fluid overload. All but two patients had a normal cardiac index $\left(>2.5 \mathrm{ml} / \mathrm{min}\right.$ per $\left.\mathrm{M}^{2}\right)$ (Table I), two patients had a slightly reduced stroke volume index $\left(<30 \mathrm{ml} / \mathrm{M}^{2}\right)$, and one patient had elevated end-diastolic volume $\left(>110 \mathrm{ml} / \mathrm{M}^{2}\right)$. All had a low ejection fraction $(<0.60)$, a hemodynamic feature characteristic of the resting state in the human cardiac allograft recipient (5). Their medications included prednisone, azathioprine, dipyridamole, and sodium warfarin; none was taking digoxin or other cardioactive drugs. At the time of surgery, each patient had two temporary 
electrodes sutured high in the interatrial groove (of the donor atria in cardiac allograft recipients) and exteriorized to the chest wall for use in the postoperative period. No intraoperative or postoperative complications resulted from the use of these temporary atrial pacing electrodes.

Myocardial dynamics measurements. The use of intramyocardial markers to assess myocardial dynamics noninvasively has been described previously (6). During surgery, tiny tantalum coils $(1.5 \times 0.85-\mathrm{mm})$ were inserted into the mid left ventricular wall in seven locations (at the apex, and at three equidistant points from apex to base along the anterolateral and inferior margins), thereby outlining the left ventricular cavity as it is seen in the $30^{\circ}$ right anterior oblique projection. Two silver tantalum clips were placed in the aortic adventitia, $3 \mathrm{~cm}$ above the aortic valve to serve as reference points from which to delineate the anterior and posterior aspects of the aortic valve in the right anterior oblique projection. Left ventricular volumes and dynamics were established by analysis of the motion of myocardial markers throughout the cardiac cycle. The markers were visualized by single plane $\left(30^{\circ}\right.$ right anterior oblique projection) cardiac cinefluoroscopy using a Philips $300 \mathrm{~mA}$ generator with a Philips 9-in. intensifier (Philips Electronic Instruments, Inc., Mahwah, N. J.) coupled to an Ampex DR 10A videodisk recorder (Ampex Corp., Redwood City, Calif.) at $30 \mathrm{frames} / \mathrm{s}$. An analogue electrocardiogram signal was recorded on the video image to allow identification of end diastole by the peak of the $R$ wave. At the conclusion of each fluoroscopic study, the video recordings were replayed frame by frame (stop motion), the XY coordinates of the marker images were digitized with a Tektronix light-pen (Tektronix, Inc., Beaverton, Ore.) coupled to a HewlettPackard 2115A minicomputer (Hewlett-Packard Co., Palo Alto, Calif.) and corrected for magnification of the radiographic system (7), and calculations of volume and velocity of shortening made with a CDC-6400 digital computer (Control Data Corp., Minneapolis, Minn.). Left ventricular volumes were calculated from corrected marker coordinates by the single plane area length method of Sandler and Dodge (8). Volumes computed from the intramyocardial marker coordinates include the volume of myocardium between the markers and the endocardial surface, and these were corrected with a regression equation obtained from an earlier comparison of volumes obtained from simultaneous marker analysis and left ventriculograms (9). End-diastolic volume (EDV) ${ }^{1}$ and endsystolic volume were derived from the maximum and the minimum, respectively, of the instantaneous volume curve. Stroke volume (SV) was calculated as the difference between EDV and end-systolic volume. Velocity of circumferential fiber shortening (VCF) was defined as the rate of change of the average ventricular diameter, calculated for each frame as one-third the sum of the six minor radii, from the maximum average ventricular diameter within $50 \mathrm{~ms}$ of the $R$ wave to the average diameter $167 \mathrm{~ms}$ (five frames) later, normalized for the maximum average ventricular diameter. This measure of VCF represents a modification of previous methods used to determine the velocity of fiber shortening in unanesthetized man (10-12).

Experimental protocol. To establish the basal myocardial dynamic characteristics of the patient (Table I), at least three consecutive beats during spontaneous sinus rhythm were recorded fluoroscopically, and resultant measurements averaged. The experimental protocol then proceeded as illustrated

${ }^{1}$ Abbreviations used in this paper: EDV, end-diastolic volume; $\mathrm{SV}$, stroke volume; VCF, velocity of circumferential fiber shortening.

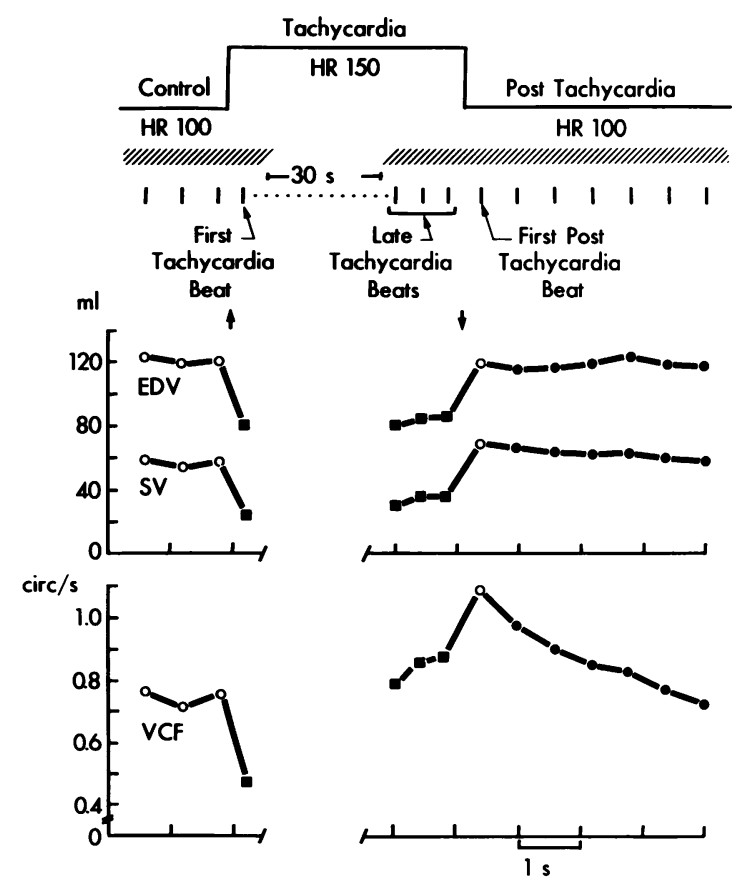

FiguRE 1 (Top panel) Schematic illustration of experimental protocol. Continuous cinefluoroscopy (shaded area) recorded control paced beats and the first tachycardia beat. After at least $30 \mathrm{~s}$ of uninterrupted tachycardia, cinefluoroscopy was resumed to encompass a trio of late tachycardia beats, the first posttachycardia beat, and sequential posttachycardia beats. The arrows emphasize the time at which pacing frequency was abruptly increased $(\uparrow)$ and decreased $(\downarrow)$. (Lower panels) Beat-to-beat measurements of EDV, SV, and VCF obtained from a patient in group II during a change in heart rate of 50 beats/min. EDV of the first posttachycardia beat was similar to that of control beats at the same frequency. EDV of the first tachycardia beat was similar to that of late tachycardia beats. Open circles $(O)$ and closed squares ( $\square$ ) indicate beats used for comparison at the larger EDV and smaller EDV, respectively. HR, heart rate; circ, circumference.

in Fig. 1. Continuous recordings were obtained during stable atrial pacing (Digital Stimulator, Bloom Associates, Narberth, $\mathrm{Pa}$.) at twice diastolic threshold at a rate just above the intrinsic sinus rate (control beats) and while the rate was abruptly increased by approximately 50 beats/min (tachycardia beats). After 30-45 s of pacing at the rapid rate, fluoroscopic recording was resumed and the rate was abruptly reduced back to the initial paced rate. Recording was continuous until the videodisk space was exhausted (usually 6-10 cardiac cycles after the reduction in rate). An electrocardiogram was continuously recorded to determine precisely the cycle length at each rate (slow paced and rapid paced). During the abrupt reduction in frequency, the pacemaker functioned so that the RR interval preceding the first posttachycardia beat was occasionally slightly shorter (mean, $33 \mathrm{~ms}$; range, 0-80 ms) than control beats, but was never longer. Thus, the "recuperative" effect of Woodworth (13) can be excluded from consideration. In four cardiac allograft recipients, the study was repeated with increments in heart rate of approximately 15 and $30 \mathrm{beats} / \mathrm{min}$ to determine whether a relationship existed between the magnitude of the change in frequency of contraction and the contractile response. Aortic pressure was 
measured in five patients (with a fluid-filled cathetertransducer system in four, and a high fidelity pressure manometer in one) during seven abrupt increases and decreases in pacing frequency to determine aortic pressures at each pair of conditions (slow paced and rapid paced).

Data analysis. To control for the altered left ventricular dimension that occurs with the change in frequency of contraction of the intact heart (Fig. 1), taking into account the observation that the first beat after a sudden change in rate retains the frequency characteristics of the previous rate $(2,14)$, the first beat after the increase in rate (first tachycardia beat) was compared with the average of three beats recorded after prolonged pacing (late tachycardia beats) at the faster rate. Similarly, the first beat after reducing the frequency of contraction (first posttachycardia beat) was compared with the average of three beats recorded initially at the slower paced rate (control beats). Sequential beats after reducing the rate were examined to analyze the decay of the positive inotropic effect of tachycardia, and to confirm the assumption that a frequency effect persists during the first beat after a sudden change in rate.

For each group of patients, a Student's $t$ test for paired data was used to compare values obtained during the first tachycardia beat with the average of values obtained during late tachycardia beats. Similarly, a paired $t$ test was used to compare the average of values obtained during control beats with that obtained during the first posttachycardia beat. The significance of the mean percentage of change in values from first tachycardia beat to late tachycardia beats and from control to first posttachycardia beat between the two groups was tested by a one-way analysis of variance.

All patients gave informed consent for insertion of myocardial markers and for completion of the physiologic studies in accordance with the regulations of the Stanford

TABLE II

Myocardial Dynamic Data during Change in Heart Rate of $50.4 \pm 2.6$ Beats/Min

\begin{tabular}{|c|c|c|c|c|c|c|c|c|c|c|c|c|}
\hline \multirow[b]{2}{*}{ Patient } & \multicolumn{2}{|c|}{ EDV } & \multicolumn{2}{|c|}{ sv } & \multicolumn{2}{|c|}{ VCF } & \multicolumn{2}{|c|}{ EDV } & \multicolumn{2}{|c|}{ SV } & \multicolumn{2}{|c|}{ VCF } \\
\hline & $\mathrm{FT}^{*}$ & LT & FT & LT & FT & LT & C & PT & C & PT & C & PT \\
\hline
\end{tabular}

Patients with innervated hearts

\begin{tabular}{|c|c|c|c|c|c|c|c|c|c|c|c|c|}
\hline 1 & 51 & 63 & 15 & 33 & 0.56 & 1.16 & 65 & 66 & 35 & 39 & 1.14 & 1.50 \\
\hline 2 & 46 & 44 & 26 & 25 & 0.91 & 1.09 & 51 & 52 & 32 & 33 & 1.09 & 1.29 \\
\hline 3 & 98 & 97 & 27 & 30 & 0.59 & 0.68 & $\ddagger$ & $\ddagger$ & $t$ & + & $\$$ & $t$ \\
\hline 4 & $t$ & $t$ & $\ddagger$ & $t$ & $\$$ & $\ddagger$ & 96 & 92 & 48 & 48 & 0.89 & 1.23 \\
\hline 5 & 77 & 75 & 14 & 21 & 0.29 & 0.66 & 87 & 85 & 33 & 35 & 0.62 & 0.87 \\
\hline 6 & 70 & 78 & 11 & 31 & 0.32 & 0.73 & 85 & 88 & 37 & 42 & 0.75 & 1.06 \\
\hline 7 & 50 & 51 & 18 & 19 & 0.66 & 0.62 & 60 & 55 & 27 & 25 & 0.77 & 0.84 \\
\hline 8 & 95 & 108 & 6 & 20 & 0.41 & 0.73 & 122 & 126 & 36 & 45 & 0.43 & 0.73 \\
\hline 9 & 95 & 93 & 22 & 26 & 0.47 & 0.65 & 103 & 105 & 32 & 36 & 0.63 & 0.82 \\
\hline Mean & 73 & 76 & 17 & 26 & 0.53 & 0.79 & 84 & 84 & 35 & 38 & 0.79 & 1.04 \\
\hline$( \pm$ SEM $)$ & 7.8 & 8.0 & 2.6 & 1.9 & 0.07 & 0.07 & 8.4 & 8.9 & 2.2 & 2.6 & 0.08 & 0.10 \\
\hline$P$ & \multicolumn{2}{|c|}{ NS } & \multicolumn{2}{|c|}{$<0.025$} & \multicolumn{2}{|c|}{$<0.01$} & \multicolumn{2}{|c|}{ NS } & \multicolumn{2}{|c|}{$<0.05$} & \multicolumn{2}{|c|}{$<0.001$} \\
\hline Mean $\%$ change & \multicolumn{2}{|c|}{5.4} & \multicolumn{2}{|c|}{78.6} & \multicolumn{2}{|c|}{63.5} & \multicolumn{2}{|c|}{-0.3} & \multicolumn{2}{|c|}{8.1} & \multicolumn{2}{|c|}{34.9} \\
\hline$( \pm$ SEM $)$ & \multicolumn{2}{|c|}{3.7} & \multicolumn{2}{|c|}{32.8} & \multicolumn{2}{|c|}{18.9} & \multicolumn{2}{|c|}{1.6} & \multicolumn{2}{|c|}{3.4} & \multicolumn{2}{|c|}{6.4} \\
\hline \multicolumn{13}{|c|}{ Patients with denervated hearts } \\
\hline 10 & 53 & 53 & 12 & 18 & 0.50 & 0.73 & 66 & 61 & 27 & 29 & 0.66 & 1.08 \\
\hline 11 & 59 & 61 & 20 & 22 & 0.79 & 0.99 & 82 & 81 & 39 & 39 & 1.17 & 1.28 \\
\hline 12 & 94 & 88 & 32 & 38 & 0.85 & 1.01 & 126 & 99 & 63 & 53 & 1.02 & 1.20 \\
\hline 13 & 29 & 33 & 10 & 18 & 0.53 & 1.18 & 45 & 41 & 26 & 28 & 0.84 & 1.31 \\
\hline 15 & 46 & 44 & 14 & 19 & 0.47 & 0.87 & 71 & 67 & 35 & 39 & 0.74 & 1.08 \\
\hline 16 & 58 & 65 & 16 & 21 & 0.61 & 0.86 & 90 & 82 & 41 & 41 & 0.85 & 1.31 \\
\hline 17 & 46 & 39 & 14 & 13 & 0.38 & 0.74 & 54 & 59 & 27 & 33 & 0.80 & 1.29 \\
\hline 18 & 72 & 72 & 26 & 27 & 0.67 & 0.98 & 87 & 81 & 39 & 39 & 0.79 & 1.18 \\
\hline Mean & 57 & 57 & 18 & 22 & 0.60 & 0.92 & 78 & 71 & 37 & 38 & 0.86 & 1.22 \\
\hline$( \pm$ SEM $)$ & 6.9 & 6.5 & 2.7 & 2.7 & 0.06 & 0.05 & 8.9 & 6.4 & 4.3 & 2.8 & 0.06 & 0.04 \\
\hline$P$ & \multicolumn{2}{|c|}{ NS } & \multicolumn{2}{|c|}{$<0.01$} & \multicolumn{2}{|c|}{$<0.001$} & \multicolumn{2}{|c|}{ NS } & \multicolumn{2}{|c|}{ NS } & \multicolumn{2}{|c|}{$<0.001$} \\
\hline Mean $\%$ change & \multicolumn{2}{|c|}{0.5} & \multicolumn{2}{|c|}{30.2} & \multicolumn{2}{|c|}{60.0} & & & & & 44 & \\
\hline$( \pm \mathrm{SEM})$ & & & & & 13 & & & & & & & \\
\hline$P \oint$ & & & & & & & & & & & & \\
\hline
\end{tabular}

* Abbreviations: FT, first tachycardia beat; LT, late tachycardia beats; C, control beats; PT, first posttachycardia beat. † Aberrant beats during sudden change in rate precluded data collection and analysis. Data from patient 14 collected only during change in rate of 15 and 30 beats/min.

$\$$ Compared with innervated group. 
University Medical Committee on the Use of Human Subjects in Research. No complications occurred as a result of the investigation.

\section{RESULTS}

Table II contains the myocardial dynamic data obtained from 17 patients during a mean change in heart rate of $50.4 \pm 2.6$ beats $/ \mathrm{min}$. During late tachycardia beats in patients with intact cardiac innervation, $\mathrm{SV}$ and VCF were higher than in first tachycardia beats by an average of $79 \%(26 \pm 1.9$ vs. $17 \pm 2.6 \mathrm{ml}$, $P<0.025)$ and $64 \%(0.79 \pm 0.07$ vs. $0.53 \pm 0.07$ circumference/s, $P<0.01$ ), whereas EDV was only $5 \%$ larger (NS). Similarly, in patients with denervated hearts, SV and VCF were higher during late tachycardia beats than during the first tachycardia beat by an average of $30 \%(22 \pm 2.7$ vs. $18 \pm 2.7 \mathrm{ml}, P<0.01)$ and $60 \%(0.92 \pm 0.05$ vs. $0.60 \pm 0.06$ circumference/s, $P$ $<0.001$ ), whereas EDV did not change significantly. The mean percent changes for each of EDV, SV, and VCF in the denervated patients were not significantly different from those in the innervated group.

The first posttachycardia beats in the innervated group produced an average increase in SV and VCF over control beats of $8 \%(38 \pm 2.6$ vs. $35 \pm 2.2 \mathrm{ml}$, $P<0.05)$ and $35 \%(1.04 \pm 0.10$ vs. $0.79 \pm 0.08$ circumference/s, $P<0.001$ ) with no change in EDV. In the denervated group, the first posttachycardia beats produced an increase over control in VCF of $44 \%$ $(1.22 \pm 0.04$ vs. $0.86 \pm 0.06$ circumference/s, $P<0.001)$ in spite of a $6 \%$ (NS) fall in EDV. SV did not change significantly. For this analysis, also, there was no statistical difference in the mean percentage of changes for EDV, SV, and VCF between the groups.

A separate analysis of the patients within the innervated group who had wall motion abnormalities in the preoperative ventriculogram showed that their responses were similar to the group mean.

In studies on five allograft recipients, average aortic diastolic pressure of the last rapidly paced beat (which contributes to the afterload effects upon VCF of the next-first posttachycardia-beat) was $73 \pm 2 \mathrm{~mm} \mathrm{Hg}$ and that of control beats $75 \pm 2 \mathrm{~mm} \mathrm{Hg}$ (NS). Peak systolic pressures of the first posttachycardia and control beats were $120 \pm 4$ and $115 \pm 2 \mathrm{~mm} \mathrm{Hg}$, respectively (NS). Average diastolic pressure of the last control beat (which contributes to the afterload characteristics of the next-first tachycardia-beat) was $76 \pm 2 \mathrm{~mm} \mathrm{Hg}$, whereas that of late tachycardia beats was slightly higher, $80 \pm 1 \mathrm{~mm} \mathrm{Hg}, P<0.05$. Peak systolic pressures of the first tachycardia beat and late tachycardia beats were $115 \pm 2$ and $120 \pm 4$ $\mathrm{mm} \mathrm{Hg}$ (NS).

The magnitude of the change in VCF was positively related to the magnitude of increase in heart rate

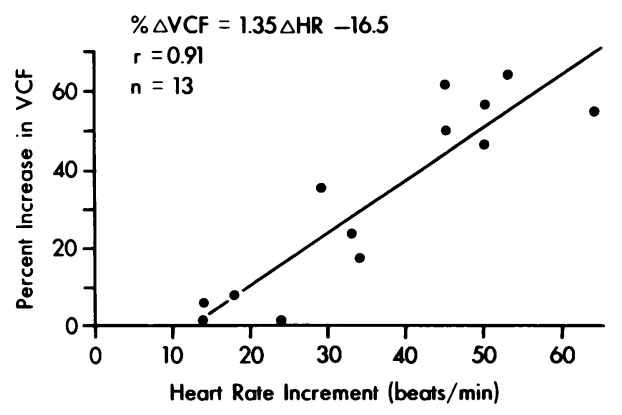

FIGURE 2 Relationship between increase in VCF (first posttachycardia beat vs. control beats) and degree of heart rate augmentation in four cardiac allograft recipients. A progressive rise in the increase of VCF occurs with progressive increments in pacing frequency. $\mathrm{HR}$, heart rate.

(Fig. 2). An analysis of all points by a least squares linear fit yielded the equation, $\% \Delta \mathrm{VCF}=1.35 \Delta$ heart rate $-16.5, r=0.91, n=13$. Fig. 3 illustrates the change in augmented VCF compared with control during sequential posttachycardia beats, as applied to a nonlinear least square fit $\left(\% \Delta \mathrm{VCF}=a e^{b(\mathrm{~s})}\right)$, for the raw data illustrated in Fig. 1. For each of 10 patients in whom six or more posttachycardia beats were recorded, the mean correlation coefficient for such an analysis was 0.90 (range $0.74-0.99$ ) and mean $t_{1 / 2}$, the half-life of the tachycardia-induced rise in $\mathrm{VCF}$, was $1.70 \pm 1.22 \mathrm{~s}( \pm \mathrm{SD})$.

\section{DISCUSSION}

The inotropic effects of changing the frequency of stimulation, described classically by Bowditch (15) and Woodworth (13), have been elaborated in isolated myocardial strips $(14,16,17)$, isolated hearts $(18-20)$, and recently in awake dogs $(2,17,21,22)$. Species differences in the response to sudden changes in the

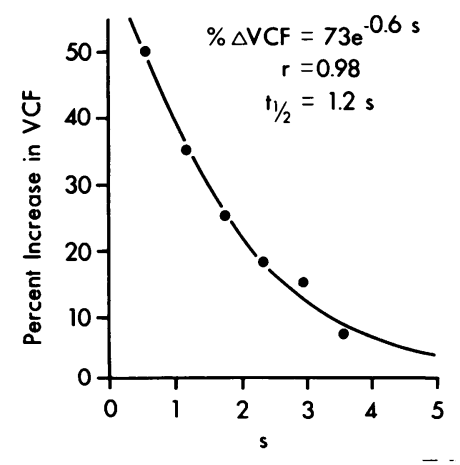

FIGURE 3 Percentage of increase in VCF over control of sequential posttachycardia beats plotted against time after suddenly reducing the rate back to control. Data are from the same patient illustrated in Fig. 1. Exponential decay in contractility is evident. 
frequency of stimulation are apparent (14), as are differences dependent upon intrinsic ventricular function $(14,22-24)$. In practice, an independent effect of cardiac frequency upon contractility in man $(25,26)$ has been difficult to establish because changes in heart rate in unanesthetized man are accompanied by changes in cardiac dimensions and systemic pressure and possibly by reflex adjustment of the cardiac contractile state. Alterations in preload and afterload that occur coincident with perturbations of the basic rate produce changes in any measured index of contractility which are independent of alterations in the inotropic state $(9,27-33)$.

Comparison of ejection phase indices from our data during steady-state tachycardia (late tachycardia) with those at the control rate illustrates the difficulty in interpreting the effect of tachycardia upon contractility. In patients with denervated hearts, for example (Table II), SV fell $41 \%$ during late tachycardia from a control of $37 \mathrm{ml}$, and VCF rose slightly from 0.86 circumference/s, whereas EDV was $27 \%$ smaller than the control of $78 \mathrm{ml}$ and systolic pressure rose slightly from 115 to $120 \mathrm{~mm} \mathrm{Hg}$. VCF, calculated by our method with a constant, or rate-independent, ejection time tends to underestimate velocity of shortening during tachycardia and is more preload dependent than other methods of measuring VCF $(12,34,35)$. Nevertheless, although these data imply that left ventricular performance is improved during tachycardia by the fact that VCF is maintained or slightly increased in spite of concurrent alterations in preload and afterload that should, independently, produce a reduction in VCF, an assessment of the true inotropic effect of tachycardia cannot be made by this type of analysis.

An alternative analysis takes advantage of an experimental design (2) which permits the comparison of an index of contractility at two frequencies of contraction while afterload and preload are constant at each frequency. An important consideration in this analysis is that the contractility effects of a given frequency of contraction persist during the first beat after a sudden change in frequency. This assumption is supported by studies in man of the contractile state of individual beats having varying RR intervals during atrial fibrillation $(36,37)$, and by the work of Koch-Weser and Blinks (14) demonstrating a gradual transition phase from one to another contractile state brought about by a change in frequency. Our results (Fig. 3) and those of Mahler et al. (2), illustrating a gradual decay of augmented inotropy after reduction in heart rate, provide further evidence in favor of this assumption. Thus, beats at control paced rate may be compared with the first posttachycardia beat which is under the influence of the augmented rate, but at a level of preload and afterload similar to control. Late tachy- cardia beats may be compared with the first tachycardia beat which is under the influence of the slower control rate and at a level of preload and afterload similar to late tachycardia. By this procedure, a pair of beats at each of two frequencies is generated for analysis.

EDV was similar for each pair of comparisons, and, except for the change in SV in the denervated group, the ejection phase indices of contractility were significantly augmented by tachycardia in both patient groups. The RR interval of the first posttachycardia beat was an average of 33 ms less than that of control beats. This resulted in a small, though not statistically significant, reduction in EDV in the denervated group, and may have counteracted the increase in SV associated with tachycardia in this group.

Inasmuch as ejection phase indices of contractility, such as SV and VCF, are sensitive to changes in afterload $(34,38)$ it is important to confirm that constant afterload is maintained over the series of beats being compared. A major determinant of afterload, when enddiastolic pressure and EDV are constant, is the pressure encountered at the time of aortic valve opening - the aortic diastolic pressure of the previous beat. These aortic valve opening pressures, measured in five patients, were similar for each pair of comparisons during several alterations of pacing frequency. Peak systolic pressures of the beats under comparison also were similar. A strict assessment of afterload and its effect upon a measure of mean $\mathrm{VCF}$ requires calculation of mean ventricular wall stress throughout ventricular ejection (39). Because a sudden increase in the frequency of contraction is known to reduce the time to development of peak tension and to shorten duration of the active state (26), integration of the stress-time relationship at each of faster and slower rates may yield differing mean stress values which would thus independently alter velocity. However, time to peak tension and duration of the active state change with the first beat after a change in rate, and persist thereafter (26). Thus, our comparison of VCF at each pair of beats is probably a valid assessment of the inotropic state.

The method used herein to calculate VCF differs from other methods $(10-12)$ in a number of respects that may influence the results. Six minor radii were used to calculate an average ventricular diameter to obtain a measure of a mean fiber shortening at the midwall in the right anterior oblique plane. This method allows segmental wall motion abnormalities to influence the shortening calculation, and avoids the contribution of wall thickening to circumferential shortening when VCF is measured at the endocardial surface (40). The fact that individual segments terminate inward motion at different times suggests that use of a shortened ejection period for VCF calculation may 
minimize effects of heterogeneous segmental relaxation. Shortening was measured over a constant time period (five cinefluoroscopic frames, or $167 \mathrm{~ms}$ ) from the maximum average ventricular diameter. This technique of calculating VCF from the dynamics of intramyocardial markers proved to be more sensitive than using shortening over the entire ejection period, where sensitivity was assessed by determining the frequency of statistically significant changes in velocity that occurred after isoproterenol administration (41). Use of a variable ejection period in the calculation of VCF in this study would yield a higher value for VCF during tachycardia because of the rate dependence of left ventricular ejection time (42), and would thereby minimize the apparent preload dependence of VCF in our method. Similar overall results as presented in this study with respect to VCF would be expected from any measure of VCF because, despite differences in actual calculation of VCF, our method adheres to the general concepts of velocity of shortening (43).

The contractile response to augmented heart rate is similar in patients with intact cardiac innervation and in those whose hearts have no extrinsic neural control. Cardiac biopsy in the allograft recipients showed no evidence of intercellular and intracellular edema or fibrosis, processes that may have modified the contractile response to tachycardia. The early postoperative state may have influenced the responses in the innervated group. A resting tachycardia of 94 beats $/ \mathrm{min}$ in this group probably represents a state of heightened sympathoadrenal activity. The mechanism responsible for frequency-dependent changes in contractility is related to alterations in the amount of calcium available to the excitation-contraction coupling system (14, 44-46), possibly by interactions with sodium transport (47). An increase is systemic catecholamine concentration, by augmenting cyclic AMP activity and subsequent release and uptake of calcum by the sarcoplasmic reticulum (48), may exaggerate the positive inotropic effect of tachycardia. This effect is not likely to be large in relation to the magnitude of change produced by tachycardia, but measurement of systemic catecholamine activity would help to clarify it. Nevertheless, in two groups - one with innervated and one with denervated hearts - whose resting hemodynamic features and cardiac function were comparable, similar inotropic responses to a given increment in heart rate suggest that reflex regulation of myocardial contractility does not acutely modulate the frequencydependent changes observed in this experimental model. Although postoperative enhancement of sympathetic tone in the innervated patients may have masked this modulation, absence of a neural effect in our patients is in concert with responses in the conscious dog after beta adrenergic blockade (2).

Fig. 4 illustrates how the data derived from this study

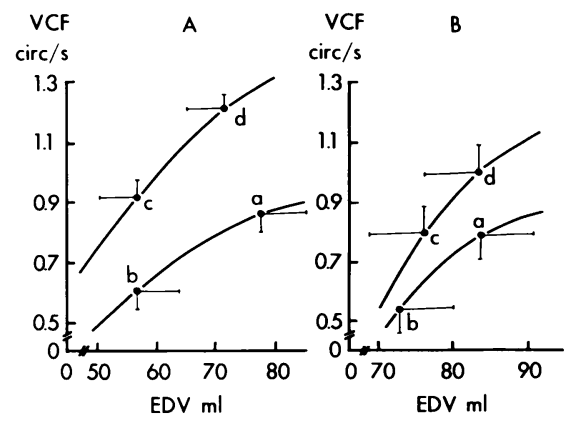

FIGURE 4 Ventricular function curves (VCF vs. EDV) in cardiac allograft recipients $(\mathrm{A})$ and patients with intact cardiac innervation (B). Control beats (point $a$ ) and the first tachycardia beat (point $b$ ) delineate the curve for the slower frequency; late tachycardia beats (point $c$ ) and the first posttachycardia beat (point $d$ ) delineate the curve for the faster frequency. A shift in the curve upward and to the left represents the positive inotropic effect of tachycardia. Circ, circumference.

may be applied to ventricular function curves to demonstrate the positive inotropic effect of increasing heart rate. A sudden reduction in EDV, as occurs during the first beat after an increase in rate, results in a fall in VCF (Fig. 4, point $a$ to point $b$ ), a manifestation of heterometric autoregulation (18). As the positive inotropic effects of activation (14) gradually accumulate at the same EDV, VCF rises to a value (point $c$ ) on a new function curve that is inscribed upward and to the left. Similarly, when control EDV is reinstated by a sudden reduction of rate, VCF rises along this function curve (to point $d$ ) which describes the frequencydependent change in contractility.

The magnitude of inotropic response to tachycardia in our study is similar to that in studies on unanesthetized animals by Mahler et al. (2) and Anderson et al. (17) but is more pronounced than that from studies by Noble and Higgins and their associates $(21,22)$. Anderson (17) suggests that the inotropic response is bimodal, separating into an early, rapidly equilibrating phase and a later, slowly equilibrating phase. Thus, divergent results among studies may be obtained because observations are made in different phases of the contractile response. Other possible explanations may be that differences exist according to species (14), the magnitude of increased rate, or in basal ventricular function $(22,23)$. Fig. 2 demonstrates that the magnitude of the change in rate is important in assessing the contractile response. Similar observations have been made in isolated muscle $(14,49)$ and conscious animals $(2,17)$ and in man $(36,37)$. Higgens et al. (22) showed that the inotropic response to increasing heart rate in conscious dogs was augmented during druginduced myocardial depression. Others have noted similar results obtained from analysis of postextrasystolic potentiation (14-24). Our analysis of this 
question showed a poor correlation of the magnitude of increase in VCF with basal ventricular function in 16 patients $(r=-0.54)$.

The exponential decay of positive inotropic effects of tachycardia (Fig. 3) in our patients was consistent with that described for conscious dogs (2). The order of magnitude of $t_{1 / 2}$ appears to be characteristic of the intact or conscious animal, being much shorter than that for in vitro preparations $(14,49)$.

In summary, we have demonstrated in awake man that the left ventricular contractile state can be considerably augmented by an increase in heart rate, independent of changes in other parameters influencing ventricular performance. This capacity for increasing contractility represents a certain degree of cardiac reserve whose functional significance may be as a contribution to improved performace during states of physiologic tachycardia such as exercise and emotion. Moreover, our results suggest that interpretation of inotropic drug effects on cardiac performance or of results of serial studies should be made after considering the direct contribution of the change in heart rate.

\section{ACKNOWLEDGMENT}

This work was supported by grant HL17993 from the National Institutes of Health.

\section{REFERENCES}

1. Braunwald, E., J. Ross, Jr., and E. H. Sonnenblick. 1976. Mechanisms of Contraction of the Normal and Failing Heart. Little, Brown \& Co. Inc., Boston. 2nd edition. 131.

2. Mahler, F., C. Yoran, and J. Ross, Jr. 1974. Inotropic effect of tachycardia and post-stimulation potentiation in the conscious dog. Am. J. Physiol. 227: 569-575.

3. Griepp, R. B., E. B. Stinson, P. Oyer, J. Copeland, and N. E. Shumway. 1975. Postoperative hemodynamics following aortic cross-clamping during aortocoronary bypass surgery. Circulation. 52(Suppl. 1): I-93-I-97.

4. Rider, A. K., J. G. Copeland, S. A. Hunt, J. Mason, M. J. Specter, R. A. Winkle, C. P. Bieber, M. E. Billingham, E. Dong, Jr., R. B. Griepp, J. S. Schroeder, E. B. Stinson, D. C. Harrison, and N. E. Shumway. 1975. The status of cardiac transplantation 1975. Circulation. 52: 531-539.

5. Stinson, E. B., P. K. Caves, R. B. Griepp, P. E. Oyer, A. K. Rider, and N. E. Shumway. 1975. Hemodynamic observations in the early period after human heart transplantation. J. Thorac. Cardiovasc. Surg. 69: 264-270.

6. Ingels, N. B., Jr., G. T. Daughters, II, E. B. Stinson, and E. L. Alderman. 1975. Measurement of midwall myocardial dynamics in intact man by radiography of surgically implanted markers. Cirulation. 52: 859-867.

7. Branzi, A., J. Mailhot, E. L. Alderman, and D. C. Harrison. 1972. Ultrasound determination of left ventricular position for volume angiography. Chest. 62: 29-33.

8. Sandler, H., and H. T. Dodge. 1968. The use of single plane angiocardiograms for the calculation of left ventricular volume in man. Am. Heart J. 75: 325-334.

9. Ingels, N. B., Jr., D. R. Ricci, G. T. Daughters, II, E. L. Alderman, and E. B. Stinson. 1977. Effects of heart rate augmentation on left ventricular volumes and cardiac output of the transplanted human heart. Circulation. 56(Suppl. II): II-32-II-37.

10. Glick, G., E. H. Sonnenblick, and E. Braunwald. 1965. Myocardial force-velocity relations studied in intact unanesthetized man. J. Clin. Invest. 44: 978-988.

11. Gault, J. H., J. Ross, Jr., and E. Braunwald. 1968. Contractile state of the left ventricle in man. Instantaneous tension-velocity-length relations in patients with and without disease of the left ventricular myocardium. Circ. Res. 22: 451-463.

12. Karliner, J. S., J. H. Gault, D. Eckberg, C. B. Mullins, and J. Ross, Jr. 1971. Mean velocity of fiber shortening. A simplified measure of left ventricular myocardial contractility. Circulation. 44: 323-333.

13. Woodworth, R. S. 1902. Maximal contraction, "staircase" contraction, refractory period, and compensatory pause of the heart. Am. J. Physiol. 8: 213-249.

14. Koch-Weser, J., and J. R. Blinks. 1963. The influence of the interval between beats on myocardial contractility. Pharmacol. Rev. 15: 601-625.

15. Bowditch, H. P. 1871. Uber die Eigenthumlichkeiten der Reizbarkeit, welche die Muskelfasern des Herzen zeigen. Ber. Konigl. Sachs. Ges. Wiss. 23: 652-689.

16. Sonnenblick, E. H. 1962. Force-velocity relations in mammalian muscle. Am. J. Physiol. 202: 931-939.

17. Anderson, P. A. W., J. S. Rankin, C. E. Arentzen, R. W. Anderson, and E. A. Johnson. 1976. Evaluation of the force-frequency relationship as a descriptor of the inotropic state of canine left ventricular myocardium. Circ. Res. 39: 832-839.

18. Sarnoff, S. J., J. H. Mitchell, J. P. Gilmore, and J. P. Remensnyder. 1960. Homeometric autoregulation in the heart. Circ. Res. 8: 1077-1091.

19. Mitchell, J. H., A. G. Wallace, and N. S. Skinner, Jr. 1963. Intrinsic effects of heart rate on left ventricular performace. Am. J. Physiol. 205: 41-48.

20. Graham, T. P., Jr., W. J. Powell, Jr., R. L. Clancy, and J. P. Gilmore. 1967. Characterization of the frequencyforce relationship in the dog atrium in situ. Circ. Res. 20: 338-348.

21. Noble, M. I. M., J. S. Wyler, E. N. C. Milne, D. Trenchard, and A. Guz. 1969. Effects of changes in heart rate on left ventricular performance in conscious dogs. Circ. Res. 24: 285-295.

22. Higgins, C. B., S. F., Vatner, D. Franklin, and E. Braunwald. 1973. Extent of regulation of the heart's contractile state in the conscious dog by alteration in the frequency of contraction. J. Clin. Invest. 52: 1187-1194.

23. Hajdu, S. 1971. Absence of Bowditch phenomena in the ventricular muscle of hamsters with hereditary cardiomyopathy. Am. Heart J. 81: 781-789.

24. Frommer, P. L., B. F. Robinson, and E. Braunwald. 1966. Paired electrical stimulation. A comparison of the effects on performance of the failing and unfailing heart. Am. J. Cardiol. 18: 738-744.

25. Sonnenblick, E. H., E. Braunwald, J. F. Williams, Jr., and G. Glick. 1965. Effects of exercise on myocardial force-velocity relations in intact unanesthetized man: relative roles of changes in heart rate, sympathetic activity, and ventricular dimensions. J. Clin. Invest. 44: $2051-2062$.

26. Sonnenblick, E. H., A. G. Morrow, and J. F. Williams, Jr. 1966. Effects of heart rate on the dynamics of force development in the intact human ventricle. Circulation. 33: 945-951.

27. Rushmer, R. F. 1959. Constancy of stroke volume in ventricular responses to exertion. Am. J. Physiol. 196: 745-750. 
28. Bristow, J. D., R. E. Ferguson, F. Mintz, and E. Rapaport. 1963. The influence of heart rate on left ventricular volume in dogs. J. Clin. Invest. 42: 649-655.

29. Glick, G., J. F. Williams, Jr., D. C. Harrison, A. G. Morrow, and E. Braunwald. 1966. Cardiac dimensions in intact unanesthetized man. VI. Effects of changes in heart rate. J. Appl. Physiol. 21: 947-958.

30. Tsakiris, A. G., D. E. Donald, R. E. Sturm, and E. H. Wood. 1969. Volume, ejection fraction, and internal dimensions of left ventricle determined by biplane videometry. Fed. Proc. 28: 1358-1367.

31. Leighton, R. F., S. J. Zaron, J. L. Robinson, and A. M. Weissler. 1969. Effects of atrial pacing on left ventricular performance in patients with heart disease. Circulation. 40: $615-622$.

32. Quinones, M. A., W. H. Gaasch, and J. K. Alexander. 1976. Influence of acute changes in preload, afterload, contractile state and heart rate on ejection and isovolumic indices of myocardial contractility in man. Circulation. 53: 293-302.

33. Powers, E. R., J. R. Foster, and W. J. Powell, Jr. 1976. Interaction of interval-force relationship with aortic pressure and stroke volume. Am.J. Physiol. 230: 893-900.

34. Mahler, F. H., J. Ross, Jr., R. A. O'Rourke, and J. W. Covell. 1975. Effects of changes in preload, afterload and inotropic state on ejection and isovolumic phase measures of contractility in the conscious dog. Am. J. Cardiol. 35: 626-634.

35. Morton, M. J., J. H. McAnulty, and S. H. Rahimtoola. 1978. "Ventricular function curve" from a single diagnostic left ventriculogram: technique results and value. Am. J. Cardiol. 41: 710-717.

36. Edmands, R. E., K. Greenspan, and C. Fisch. 1970. The role of inotropic variation in ventricular function during atrial fibrillation. J. Clin. Invest. 49: 738-746.

37. Karliner, J. S., J. H. Gault, R. J. Bouchard, and J. Holzer. 1974. Factors influencing the ejection fraction and the mean rate of circumferential fiber shortening during atrial fibrillation in man. Cardiovasc. Res. 8: 18-25.

38. Ross, J., Jr., J. W. Covell, E. H. Sonnenblick, and E. Braunwald. 1966. Contractile state of the heart character- ized by force-velocity relations in variably afterloaded and isovolumic beats. Circ. Res. 18: 149-163.

39. Sasayma, S., D. Franklin, and J. Ross, Jr. 1977. Hyperfunction with normal inotropic state of the hypertrophied left ventricle. Am. J. Physiol. 232: H418-H425.

40. Gould, K. L., J. W. Kennedy, M. Frimer, G. H. Pollock, and H. T. Dodge. 1976. Analysis of wall dynamics and directional components of left ventricular contraction in man. Am. J. Cardiol. 88: 322-331.

41. Daughters, G. T., N. B. Ingels, E. L. Alderman, and E. B. Stinson. 1976. Calculation of circumferential fiber shortening velocity from directly measured left ventricular dimensions. Proc. Annu. Conf. Eng. Med. Biol. 29: 269A. (Abstr.)

42. Weissler, A. M., L. C. Harris, and G. D. White. 1963. Left ventricular ejection time index in man. J. Appl. Physiol. 18: 919-923.

43. Covell, J. W., J. Ross, Jr., E. H. Sonnenblick, and E. Braunwald. 1966. Comparison of the force-velocity relation and the ventricular function curve as measures of the contractile state of the intact heart. Circ. Res. 19: 364-372.

44. Morad, M., and Y. Goldman. 1973. Excitation-contraction coupling in heart muscle: membrane control of development of tension. Prog. Biophys. Mol. Biol. 27: 257-313.

45. Niedergerke, R. 1956. The "staircase" phenomenon and the action of calcium on the heart. J. Physiol. (Lond.). 134: 569-583.

46. Niedergerke, R. 1957. The rate of action of calcium ions on the contraction of the heart. J. Physiol. (Lond.). 138: 506-515.

47. Langer, G. A. 1968. Ion fluxes in cardiac excitation and contraction and their relation to myocardial contractility. Physiol. Rev. 48: 708-757.

48. Tsien, R. W., W. Giles, and P. Greengard. 1972. Cyclic AMP mediates the effects of adrenaline on cardiac Purkinje fibers. Nature (Lond.). 240: 181-183.

49. Rosin, H., and A. Farah. 1955. Post-stimulation potentiation of contractility in the isolated auricle of the rabbit. Am. J. Physiol. 180: 75-82. 